\title{
KARAKTERISASI KECEPATAN PUTARAN BERDASARKAN RASIO INPUT BAHAN BAKAR PADA GENERATOR SET DUAL FUEL (GASOLINE - BIOGAS) MENGGUNAKAN JARINGAN SYARAF TIRUAN
}

\author{
Arief Abdurrakhman ${ }^{1}$, Dhirga Kurniawan ${ }^{2}$, Mohammad Berel Toriki ${ }^{3}$, Bambang Lelono \\ Widjiantoro ${ }^{4}$ \\ ${ }^{1}$ Teknik Instrumentasi, Institut Teknologi Sepuluh Nopember \\ 2,3,4 Teknik Fisika, Institut Teknologi Sepuluh Nopember \\ Email: 1ariefabdurrakhman@gmail.com
}

\begin{abstract}
Abstrak
Abstrak - Saat ini konsumsi energi di Indonesia mengalami peningkatan sehingga pemanfaatan energi terbarukan lebih dikembangkan untuk memenuhi proyeksi kebutuhan energi masa depan. Salah satu sumber energi terbarukan yang sedang dikembangkan penggunaannya adalah biogas, khususnya untuk biogas skala rumah tangga. Implementasi biogas pada skala rumah tangga ada beberapa macam, salah satunya adalah penggunaan biogas sebagai bahan bakar generator untuk menghasilkan listrik. Bahan bakar generator bisa menggunakan biogas secara penuh atau bahan bakar campuran gasoline dengan biogas. Generator set listrik dengan bahan bakar ganda gasoline-biogas dapat menghemat penggunaan gasoline sebagai bahan bakar dan juga dapat menigkatkan performansi generator. Rasio campuran gasoline-biogas berpengaruh terhadap performansi engine, salah satunya pada kecepatan putar. Namun saat ini rasio campuran gasoline dengan biogas masih diatur secara manual pada penggunaan biogas skala rumah tangga. Berdasarkan pada kondisi tersebut, maka dalam penelitian ini dikembangkan metode jaringan syaraf tiruan / artificial neural networks (ANN) yang bertujuan untuk mencari rasio optimal agar mendapatkan karakterisasi kecepatan putar generator set dengan nilai performansi engine terbaik. Sebanyak 300 variasi data diolah menggunakan JST $75 \%$ untuk training dengan jumlah hidden node 100 nilai net.trainParam.goal $=0.0001$, net.trainParam.Ir $=0.01$, dan net.trainParam.epochs $=1000$, serta $25 \%$ untuk uji. Penelitian ini menghasilkan nilai RMSE training sebesar 10,4812 pada node ke 55 dan nilai RMSE uji sebesar 5,8301 dengan hasil kecepatan putar 3445,87, dan mendapatkan rasio terbaik pada gasoline 0,012 $\mathrm{L} / \mathrm{menit}$ dan biogas $5 \mathrm{~L} / \mathrm{menit}$.
\end{abstract}

Kata Kunci: Jaringan Syaraf Tiruan, Generator Dual Fuel, Gasoline-Biogas

\begin{abstract}
Abstract-- Currently, energy consumption in Indonesia has increased so that the utilization of renewable energy is more developed to supply projections for future energy needs. One of the renewable energy sources that is being developed is biogas, especially for household-scale biogas. There are several types of biogas implementation at the household scale, one of which is the use of biogas as generator fuel to produce electricity. Fuel generators can use biogas in full or mix gasoline with biogas fuel. Electric generator sets with dual gasoline-biogas fuel can save the use of gasoline as fuel and can also increase the performance of generators. The gasoline-biogas mixture ratio affects engine performance, one of which is the rotational speed. However, at present the ratio of gasoline to biogas is still manually regulated on household scale biogas usage. Based on these conditions, the artificial neural networks (ANN) method was developed in this study which aims to find the optimal ratio in order to get the generator set rotational speed characterization with the best engine performance value. A total of 300 variations of data were processed using 75\% for training with the number of hidden nodes 100 net.trainParam.goal value $=0.0001$, net.trainParam.lr $=0.01$, and net.trainParam.epochs $=$
\end{abstract}


1000, and 25\% for the test. This study produced a RMSE training value of 10.4812 at node 55 and a test RMSE value of 5.8301 with a rotational speed of 3445.87, and obtained the best ratio of $0.012 \mathrm{~L} / \mathrm{min}$ gasoline and $5 \mathrm{~L} / \mathrm{min}$ biogas. .

Keywords: Artificial Neural Network, Generator Dual Fuel, Gasoline-Biogas

\section{PENDAHULUAN}

Konsumsi energi final di Indonesia mengalami peningkatan dari 79 juta TOE menjadi 134 juta TOE (Tonnes Oil Equivalent) atau tumbuh rata-rata sebesar $5,5 \%$ per tahun dalam sepuluh tahun terakhir (2003-2013). Sejalan dengan meningkatnya konsumsi energi tersebut, maka penyediaan energi primer juga mengalami kenaikan (Abdurrahman, A,et.al, 2014). Namun upaya untuk memenuhi kebutuhan energi di dalam negeri antara lain terkendala oleh ketersediaan infrastruktur energi seperti pembangkit listrik, kilang minyak, pelabuhan, serta transmisi dan distribusi (Yamasaki, Y, et. al, 2013).

Melonjaknya harga minyak bumi dunia dan diikuti dengan meningkatnya harga bahan bakar fosil lain. Di sisi lain, isu lingkungan global yang menuntut tingkat kualitas lingkungan yang lebih baik, mendorong berbagai pakar energi untuk mengembangkan energi yang lebih ramah lingkungan dan mendukung keamanan pasokan berkesinambungan. Saat ini cadangan energi fosil sudah semakin menipis dan pencarian sudah sangat sulit dilakukan, bahkan diprediksi 2030 akan betul-betul menjadi nett importer energi, sebab keseimbangan antara produksi dan konsumsi energi domestik terjadi di tahun 2030. Mulai tahun ini produksi energi dalam negeri (fosil dan EBT) sudah tidak mampu lagi memenuhi konsumsi domestik dan Indonesia berubah status menjadi negara pengimpor energi (Abdurrahman, A,et.al, 2014).

Hal tersebut membuat peranan renewable energy lebih dikembangkan apalagi Indonesia memiliki potensi besar untuk itu. Berdasarkan jenisnya, Indonesia dianugerahi kekayaan sumber daya energi mulai dari hydro, panas bumi, biomassa, surya, angin, hingga samudra. Namun yang disayangkan kekayaan tersebut belum banyak dimanfaatkan sebagai sumber energi yang dapat menggantikan sumber-sumber energi fosil yang semakin lama sudah semakin menipis. Salah satu sumber energi terbarukan yang sedang digencarkan penggunaannya adalah biogas, khususnya untuk skala rumah tangga. Namun pengembangan biogas di Indonesia masih relatif lambat karena berbagai faktor, mulai dari masyarakat yang masih kurang nyaman dengan energi dari kotoran hingga masalah pemurnian biogas serta pengimplementasian pada generator set (Setiawan, A. I, 2002).

Berdasarkan data dari Direktorat Jenderal Peternakan dan Kesehatan Hewan, angka sementara jumlah sapi potong pada tahun 2015 mencapai 15 juta ekor. Satu ekor sapi mampu menghasilkan kotoran padat dan cair sebanyak 23,6 kg/hari dan 9,1 kg/hari. Dalam $1 \mathrm{~kg}$ kotoran ternak sapi/kerbau menghasilkan 0,023-0,040 m3 biogas. Sehingga nilai maksimal potensi biogas dari kotoran sapi adalah sebesar 14,16 juta $\mathrm{m} 3$ /hari. Metana sebesar 9,912 juta m3/hari dan CO2 sebesar 4,248 juta m3/hari. Dengan kata lain, dalam waktu setahun Indonesia akan menyumbang $\mathrm{CO} 2$ sebesar 1,55 milyar $\mathrm{m} 3$ atau setara 2,77 juta ton per tahun dan metana sebesar 3,617 milyar $\mathrm{m} 3$ atau setara 6,466 juta ton per tahun. Efek gas rumah kaca pada gas metana setara dengan 21 kali $\mathrm{CO} 2$. Artinya dengan adanya sumbangan gas metana ini, akan setara dengan CO2 sebesar 135,8 juta ton per tahun, dan jika ditotal Indonesia akan menyumbang $\mathrm{CO} 2$ sebesar 138,573, yang berarti jika kotoran sapi di Indonesia tidak dimanfaatkan, maka akan sangat berdampak negatif bagi keberlangsungan makhluk hidup karena efek dari semakin menipisnya ozon (Harahap, F, 1980) (Zed, F, et. al. 2014).

Generator set bahan bakar ganda (dual fuel) adalah mesin standar gasoline yang ditambahkan bahan bakar lain yang dalam hal ini adalah biogas pada intake manifold dan penyalaan bahan bakar dilakukan oleh semprotan gasoline yang disebut pilot fuel. Secara sederhana bahan bakar cair atau gas dapat dimasukkan dengan membuat lubang pada intake manifold mesin gasoline. Tergantung dari jenis bahan bakar yang ditambahkan, apabila jenis liquid/cair yang digunakan seperti ethanol atau methanol maka perlu dibuatkan karburator seperti pada mesin gasoline atau dipompa dengan tekanan tertentu dan dikabutkan saat masuk ke saluran udara masuk mesindiesel. Sedangkan untuk bahan bakar gas tidak diperlukan lagi karburator karena bahan bakar gas sudah 
mempunyai tekanan sendiri (Awogbemi, et. al, 2015).

Sistem dual fuel selain menghemat penggunaan gasoline sebagai bahan bakar, biaya produksi dapat ditekan, juga biaya modifikasi generator set relatif lebih murah dibanding mengkonversi ke mesin gas (gas engine). Lebih jauh lagi, penerapan biogas dengan sistem dual fuel pada generator set dapat meningkatkan unjuk kerja dan efisiensi mesin. Pemanfaatan biogas ke generator set tidak akan mengubah komposisi peralatan mesin dan hanya menambah peralatan sistem mixer ventury pada saluran isap. Sedangkan penggunaan dual fuel dimaksudkan untuk mengurangi penggunaan bensin pada proses pembakaran serta meningkatkan performansi dari genset yang dapat diukur pada daya, torsi, konsumsi bahan bakar spesifik (SFC), Rasio perbandingan udara bahan bakar (AFR), efisiensi thermal, dan emisi gas buang (Chuwang, S, et.al, 2011) (Yamasaki, Y, et. al, 2013). Manfaat sistem bahan bakar ganda adalah untuk menghemat penggunaan bensin sebagai bahan bakar, biaya produksi dapat diminimalisasi, serta biaya modifikasi genset yang relatif lebih murah daripada mengonversi ke seluruh mesin gas. Selanjutnya, aplikasi biogas dengan sistem bahan bakar ganda pada genset dapat meningkatkan kinerja dan efisiensi mesin (Bastida et al., 2017). Pada penelitian lain, Verma, 2017, telah melakukan penelitian tentang pengaruh variasi dalam komposisi biogas pada kinerja mesin diesel untuk bahan bakar ganda menggunakan analisis eksergi. Variasi komposisi biogas yang digunakan adalah 93\% (BG93), 84\% (BG84), dan 75\% (BG75), dan menghasilkan total irreversibilitas dalam mesin diesel meningkat sebesar $61,44 \%$ dalam biogas dengan 93\% kandungan metana. Sedangkan Air-Fuel Ratio yang dihasilkan adalah 22,47 untuk BG 93; 16.77 untuk BG84; dan 13,49 untuk BG75.

Pada percobaan yang telah dilakukan oleh $\mathrm{Su}$ Chu-wang and Ye Shu-jian dengan menggunakan rasio input gasoline-biogas dengan rasio biogas sebesar $0 \% \quad 20 \% \quad 40 \% \quad 60 \% \quad 80 \%$ dan $100 \%$ menunjukkan hasil uji pada torsi dan daya terhadap speed $(\mathrm{Rpm})$ sedikit lebih rendah dari generator set konvensional (single fuel) (Setiawan, A. I, 2002). Pada percobaan lain yang dilakukan oleh Yudai Yamasaki dengan menggunakan rasio biogas sebesar 0\%, 20\%, 55\%, $75 \%$, dan $100 \%$. Dalam percobaan tersebut, komposisi gas biomassa adalah $63 \%$ metana dan $37 \% \mathrm{CO}_{2}$ menunjukkan hasil uji respon mencapai target speed 1700rpm lebih lambat jika dibandingkan dengan single fuel. Pada percobaan yang lainnya oleh Awogbemi dkk dengan kandungan biogas sebesar $65,25 \%, 0,65 \%, 1,63 \%$, $1,76 \%$, dan $30,71 \%$ etana $\mathrm{CH} 4$, ammonia $\mathrm{NH} 3$, karbon monoksida $\mathrm{CO}, \mathrm{H} 2 \mathrm{~S}$ hidrogen sulfida, dan $\mathrm{CO} 2$ karbon dioksida dengan perpaduan gasoline - biogas pada kecepatan 1000Rpm dan 3500Rpm pengambilan data output pada torsi dan suhu pembuangan, menunjukkan peningkatan torsi antara $6.2 \mathrm{Nm}-8.7 \mathrm{Nm}$ pada kecepatan maksimal, suhu gas buang meningkat seiring dengan kenaikan putaran mesin hal tersebut disebabkan nilai kalor gasoline sedikit lebih rendah dari pada campuran gasoline biogas (Zuhri, T, 2015).

Pada penerapan sistem dual fuel fluida gasoline dan biogas ini masih terdapat beberapa kekurangan, salah satunya yaitu kurang optimalnya operasional dari genset ketika memakai campuran input dual fuel. Dimana campuran input dual fuel ini sangat berpengaruh dalam peningkatan unjuk kerja generator set seperti peningkatan efisiensi torsi, daya, tegangan dan speed (rpm) pada generator set.

Terdapat beberapa rasio campuran gasolinebiogas yang dipergunakan untuk mendapatkan hasil peningkatan efisiensi torsi, daya, tegangan dan speed (rpm) yang mendekati performa dari generator set konvensional. Maka dari itu digunakan jaringan syaraf tiruan yang mampu untuk melakukan pelacakan atau pencarian data kecepatan generator set yang optimal dengan menggunakan metode Levenberg-Marquadt (Puspaningrum, 2006). Jaringan syaraf tiruan adalah mesin pembelajaran nonlinier yang dibangun dari berbagai elemen pemrosesan / processing elements (PE). Setiap PE menerima koneksi dari PE lain dan / atau dirinya sendiri. Interkonektivitas mendefinisikan topologi. Sinyal yang mengalir pada koneksi diskalakan oleh parameter yang dapat diatur yang disebut bobot / weight. PE menjumlahkan semua kontribusi ini dan menghasilkan output yang merupakan fungsi non-linier (statis) dari jumlah tersebut. Output PE menjadi output sistem atau dikirim ke PE yang sama atau lainnya (Gurney, 2003). Metode lovenberg-Marquadt adalah salah satu algoritma yang dapat digunakan untuk memperkirakan hasil berikutnya berdasarkan data-data yang sudah ada sebelumnya (Puspaningrum, 2006). Sistem kerja metode Lovenberg-marquadt dapat dipergunakan untuk mengetahui karakterisasi kecepatan putaran berdasarkan rasio input pada generator-set listrik dual fuel (gasoline-biogas) menggunakan jaringan syaraf tiruan untuk mencapai nilai performansi engine terbaik. 


\section{METODE}

Pada bagian ini dijelaskan mengenai langkah dan metodologi penelitian yang digunakan sebagai acuan sehingga penelitian yang dilakukan berjalan secara sistematis sesuai dengan kaidah penelitian.

a. Pengambilan data berupa data input-output yaitu flowrate inlet gasoline dan biogas sebagai data input sedangkan kecepatan putar generator set sebagai data output.

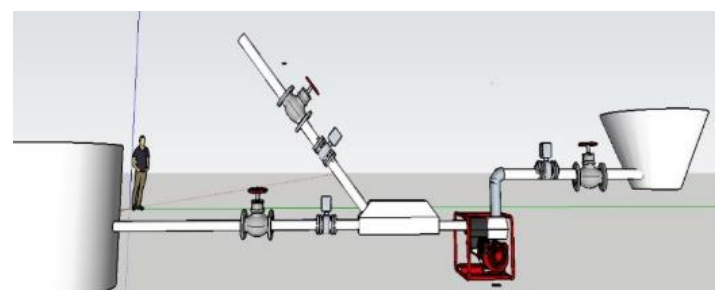

Gambar 1. Desain Sistem Keseluruhan Pada Generator Set Dual Fuel

Pengambilan data seperti yang ditunjukkan pada gambar 1 dilakukan secara real plan dengan memasang sistem sistem monitoring yang terintegrasi dengan database, sehingga hasil pengambilan data dapat di-record dan tersimpan didalam database. Pengaturan masukan antara biogas dan gasoline dilakukan melalui valve yang dipasang pada masingmasing jalur input. Perbandingan antara biogas dan gasoline yang diinjeksikan ke mesin berubah-ubah, dikarenakan untuk mencapai kecepatan putaran generator yang optimal.

Tabel 1. Parameter Generator Set

\begin{tabular}{|c|c|c|c|}
\hline No & $\begin{array}{c}\text { Parameter } \\
\text { Generator }\end{array}$ & Nilai & Satuan \\
\hline 1. & $\begin{array}{c}\text { Engine jenis spark } \\
\text { ignition }\end{array}$ & - & - \\
\hline 2. & Putaran generator & 3000 & rpm \\
\hline 3. & $\begin{array}{c}\text { Tegangan keluaran } \\
\text { (AC) }\end{array}$ & 220 & $\begin{array}{c}\text { Volt } \\
\text { AC }\end{array}$ \\
\hline 4. & $\begin{array}{c}\text { Tegangan keluaran } \\
\text { (DC) }\end{array}$ & 12 & $\begin{array}{c}\text { Volt } \\
\text { DC }\end{array}$ \\
\hline 5. & Dual fuel engine & - & - \\
\hline 6. & Daya keluaran & 1200 & watt \\
\hline
\end{tabular}

Sedangkan untuk peralatan pendukung (sistem instrumentasi) yang digunakan pada pengambilan data ini dijelaskan pada tabel II berikut.

b. Pengelompokan data input dan output untuk sistem jaringan syaraf tiruan yang akan dirancang, dimana flowrate inlet gasoline dan biogas sebagai input dan kecepatan putaran generator set yang akan dicari karakternya sebagai output.

Tabel 2. Pengelompokan Data Input Output Generator Set

\begin{tabular}{|c|l|l|}
\hline No & \multicolumn{1}{|c|}{ Alat } & \multicolumn{2}{|c|}{ Spesifikasi } \\
\hline 1. & ATmega8535 & 28 pin I/O \\
\hline 2. & MOV 2 buah & $\begin{array}{l}\text { Maksimal aliran 2 } \\
\text { liter/min }\end{array}$ \\
\hline 3. & Pipa & PVC 1/4 inch \\
\hline 4. & $\begin{array}{l}\text { Tangki } \\
\text { biogas 2 buah }\end{array}$ & $\begin{array}{l}\text { Masing-masing } \\
\text { memiliki volume 5 } \\
\text { liter }\end{array}$ \\
\hline
\end{tabular}

Tabel 3. Pengelompokan Data Input Output Generator Set

\begin{tabular}{|c|c|c|c|}
\hline No & \multicolumn{2}{|c|}{ Input generator set } & $\begin{array}{c}\text { Output } \\
\text { generator set }\end{array}$ \\
\hline \multirow{2}{*}{$\begin{array}{c}\text { Flowrate } \\
\text { gasoline } \\
\text { (L/menit })\end{array}$} & $\begin{array}{c}\text { Flowrate } \\
\text { biogas } \\
(\mathrm{L} / \mathrm{menit})\end{array}$ & $\begin{array}{c}\text { Kecepatan } \\
\text { putar }(\mathrm{rpm})\end{array}$ \\
\hline
\end{tabular}

c. Perancangan arsitektur jaringan syaraf tiruan yang digunakan adalah multi layer perceptron, dimana terdapat multi input dan single output.

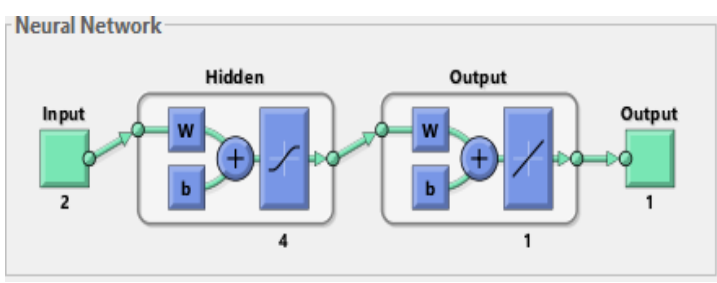

Gambar 2. Arsitektur JST yang Digunakan

d. Training jaringan syaraf tiruan dengan metode Loverberg-Marquadt yang merupakan pengembangan algoritma error backpropagation.

e. Melakukan pengujian dan testing terhadap sistem jaringan syaraf tiruan yang telah ditraining.

f. Pembagian training pada jaringan syaraf tiruan sebanyak $100 \%$ dari data yang diperoleh pembagian uji pada jaringan syaraf tiruan sebanyak $15 \%$ dari data yang diperoleh dan $10 \%$ digunakan untuk uji manual pada GUI yang telah dibuat.

g. Analisa hasil berupa kecepatan putar generator set dan karakterisasi putaran generator set.

\section{HASIL DAN PEMBAHASAN}

Pada bagian ini berisi tentang karakterisasi kecepatan putaran berdasarkan rasio input bahan bakar pada generator-set listrik dual fuel (gasoline-biogas) menggunakan jaringan syaraf 
tiruan, berdasarkan eksperimen secara langsung dengan daya yang dipergunakan pada daya sebesar 900W. Selain itu dijelaskan mengenai hasil simulasi menggunakan Jaringan Syaraf Tiruan.

a. Analisis data

Berdasarkan hasil eksperimen secara langsung diperoleh data input flowrate gasoline dan biogas dengan kecepatan putaran generator set, masing masing variabel memiliki 300 data yang telah divariasi dan diperoleh data rasio dari inputan Flowrate Gasoline dan Flowrate Biogas terhadap perubahan kecepatan putaran dengan perolehan kecepatan putaran dari $2900 \mathrm{rpm}$ hingga kecepatan putaran mencapai $3090 \mathrm{rpm}$.

b. Jaringan Syaraf Tiruan

Hasil pelatihan Jaringan Syaraf Tiruan Pelatihan terhadap model JST dengan jumlah hidden node sebanyak 100 dengan nilai net.trainParam.goal $=0.0001$, net.trainParam.lr $=0.01$, dan net.trainParam.epochs $=1000$, memberikan hasil training JST dengan 100 hidden node menghasilkan RMSE yang bernilai paling kecil pada node ke 55 yaitu sebesar 10,4812.

Dengan perolehan nilai RMSE (Root Mean Square Error) terkecil pada pelatihan dapat dilihat pada gambar 4.

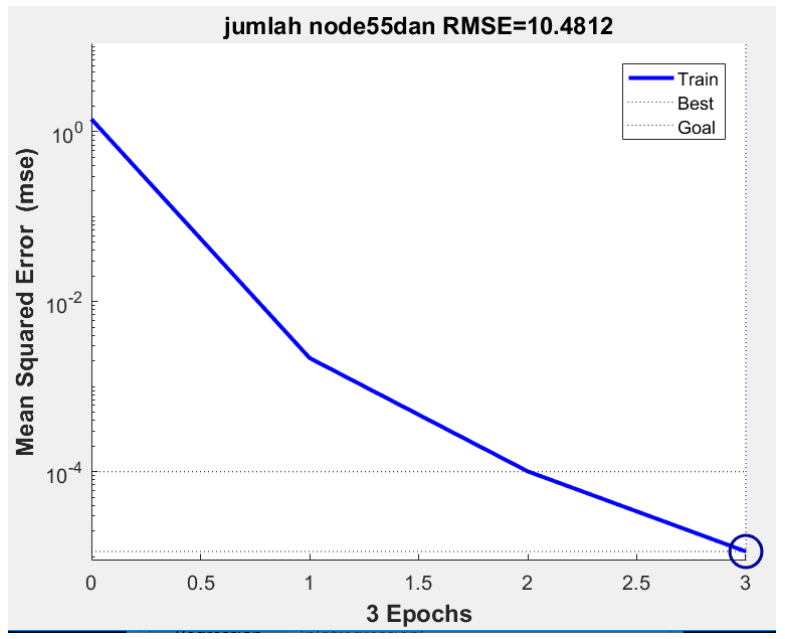

Gambar 3. Grafik Hidden Node Nilai Terkecil

Setelah memperoleh nilai RMSE pada pelatihan, dilanjutkan dengan pengujian data menggunakan perbandingan antara data yang diperoleh dengan menggunakan data yang telah diolah menggunakan JST dengan nilai RMSE sebesar 5,8301, pada grafik terdapat garis berwarna merah dan garis berwarna biru, warna merah menunjukkan target yang diinginkan dan warna biru merupakan keluaran dari pengolahan program JST yang telah dibuat yang dapat dilihat pada gambar 4 berikut ini :

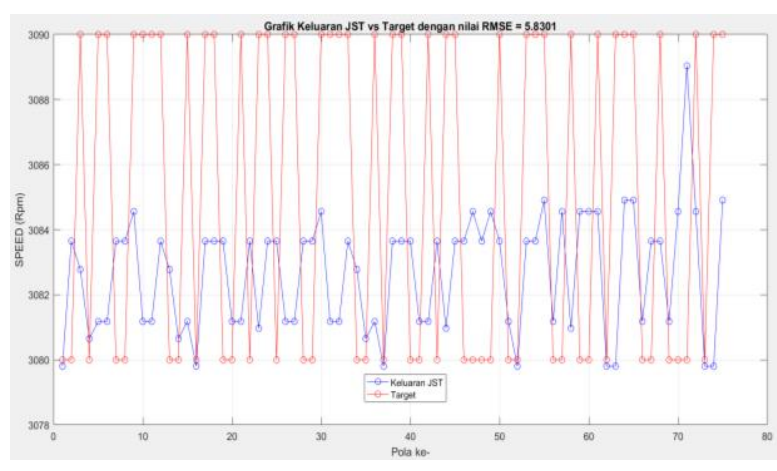

Gambar 4. Grafik Output dari JST dan Target

Pengujian data pada GUI (Graphic User Interface) yang telah dibuat dengan basis JST dengan cara memasukkan nilai input secara manual untuk dapat membandingkan nilai input dan output yang diperoleh dengan input - output dari program jaringan syaraf tiruan yang telah dibuat. Perbandingan nilai input dan output dilakukan pada semua variasi data dengan perolehan dari data JST tersebut. Berikut merupakan tampilan dari GUI yang telah dibuat untuk memasukkan input data dan menghasilkan nilai kecepatan putaran yang telah diolah menggunakan program JST, yang dapat dilihat pada gambar 5 berikut ini :

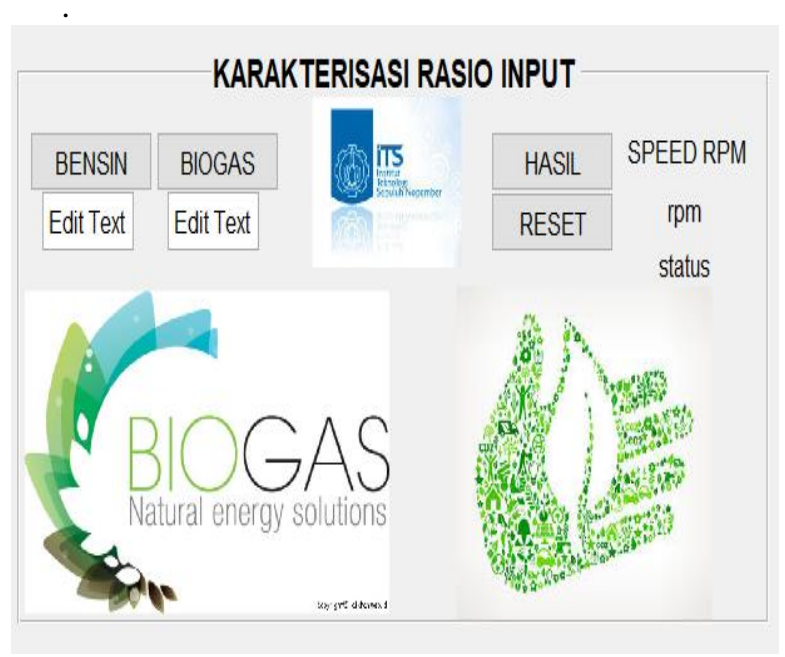

Gambar 5. Tampilan GUI Untuk Menentukan Karakteristik Rasio Input Bahan Bakar

Data awal yang telah diperoleh dimasukkan sebagai inputan pada GUI untuk mendapatkan hasil kecepatan putaran yang telah diolah dengan menggunakan program JST , dari $10 \%$ data yang telah diperoleh dari input dengan menggunakan olahan program JST, didapatkan karakter kecepatan putar terbaik sebesar 3445,86 rpm pada rasio gasoline $0,016 \mathrm{~L} /$ menit dan biogas $5 \mathrm{~L} /$ menit. 
c. Karakteristik Kecepatan Putar Generator Set dengan Rasio Input Gasoline - Biogas

Dari perolehan data rasio input gasoline biogas terhadap kecepatan putaran generayor set tanpa menggunakan JST mendapatkan hasil minimum sebesar $2900 \mathrm{rpm}$ pada rasio gasoline $0,01 \mathrm{~L} /$ menit dan biogas $0,5 \mathrm{~L} /$ menit serta hasil maksimum $3090 \mathrm{rpm}$ pada gasoline $0,16 \mathrm{~L} /$ menit dan biogas $5 \mathrm{~L} / \mathrm{menit}$, pada percobaan menggunakan GUI terhadap kecepatan putaran terendah hingga tertinggi dari masukan rasio input Gasoline-Biogas yang diperoleh menggunakan JST mendapatkan hasil speed minimum sebesar 3438,73 rpm dan hasil kecepatan putaran maksimum sebesar 3445,86 rpm. Dari data yang telah diperoleh, dengan adanya penambahan flow rate biogas setiap $\mathrm{L} /$ menit nya berpengaruh terhadap data keluaran dari GUI yang dibuat, dimana semakin meningkatnya flowrate biogas terhadap rasio gasoline maka semakin tinggi hasil keluaran kecepatan putaran yang didapatkan.

Tabel 4. Rasio Input Gasoline - Biogas Terhadap RPM yang Dihasilkan Generator Set

\begin{tabular}{|c|c|c|c|}
\hline \multicolumn{2}{|c|}{ Flow Rate (L/min) } & \multicolumn{2}{c|}{ Generator Set } \\
\hline Biogas & Gasoline & $\begin{array}{c}\text { RPM } \\
\text { (real plan) }\end{array}$ & $\begin{array}{c}\text { RPM } \\
\text { (JST) }\end{array}$ \\
\hline 0,5 & 0,01 & 2900 & 3438,02 \\
\hline 0,9 & 0,011 & 2900 & 3439,37 \\
\hline 1,1 & 0,011 & 2990 & 3439,69 \\
\hline 1,5 & 0,013 & 2950 & 3440,32 \\
\hline 2,2 & 0,013 & 3000 & 3441,43 \\
\hline 3 & 0,014 & 3070 & 3442,70 \\
\hline 3,5 & 0,011 & 3050 & 3443,50 \\
\hline 4 & 0,011 & 3090 & 3444,29 \\
\hline 4,2 & 0,011 & 3090 & 3444,60 \\
\hline 4,3 & 0,011 & 3090 & 3444,76 \\
\hline 4,4 & 0,015 & 3070 & 3444,91 \\
\hline 4,5 & 0,011 & 3090 & 3445,08 \\
\hline 4,6 & 0,015 & 3090 & 3445,23 \\
\hline 4,8 & 0,016 & 3080 & 3445,54 \\
\hline 5 & 0,012 & 3090 & 3445,87 \\
\hline
\end{tabular}

Berdasarkan tabel II diatas, dapat dibuat grafik rasio input untuk memperoleh kecepatan putaran terbaik seperti pada gambar 6 .

\section{d. Pembahasan}

Pada percobaan karakterisasi rasio input bahan bakar pada generator-set listrik dual fuel (gasolinebiogas) menggunakan jaringan syaraf tiruan digunakan beban 9 bola lampu dengan masingmasing lampu memiliki daya 100 Watt dengan total daya sebesar 900 Watt. Pada penelitian ini diperlukan data berupa flowrate gasoline (L/menit) dan flowrate biogas(L/menit) dengan output berupa kecepatan putaran. Kandungan biogas yang digunakan memiliki kandungan metan sebesar $65,32 \%$, pengambilan data awal diperoleh flowrate biogas sebesar 0,5 L/menit tanpa campuran gasoline dengan perolehan kecepatan putaran sebesar 2900 rpm. Selanjutnya dilakukan pengambilan data dengan menggunakan fungsi waktu dengan kenaikan flowrate pada setiap inputan. Pada hasil percobaan yang diperoleh mendapatkan flowrate biogas pada range 0,5 $\mathrm{L} /$ menit sampai $5 \mathrm{~L} / \mathrm{menit}$ dan pada flowrate gasoline berada pada range $0,01 \mathrm{~L} /$ menit hingga $0,016 \mathrm{~L} /$ menit, dengan percobaan yang diambil sebanyak 300 variasi data.

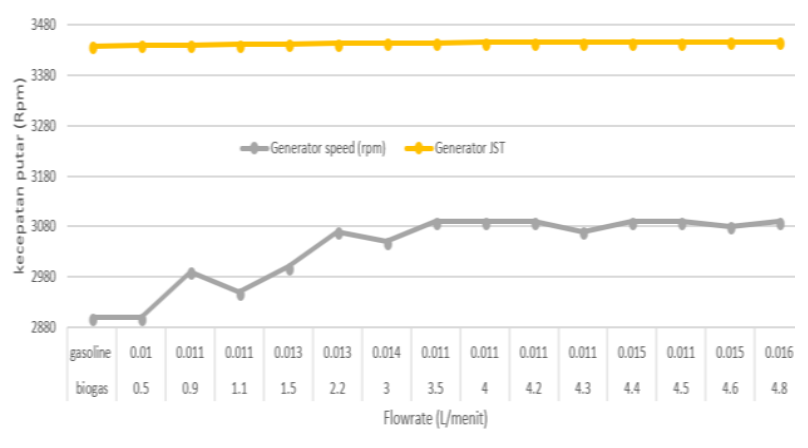

Gambar 6. Rasio Input Gasoline - Biogas Terhadap RPM yang Dihasilkan Generator Set

Setelah memperoleh data hasil percobaan, selanjutnya membuat jaringan syaraf tiruan untuk mencari rasio input dari gasoline dan biogas, pada jaringan syaraf tiruan yang dibuat terdiri dari training data, uji data, dan tampilan GUI. Dari 300 data yang diperoleh sebanyak $75 \%$ digunakan untuk proses training, $25 \%$ data digunakan pada proses uji. Dari $25 \%$ tersebut sebanyak $15 \%$ digunakan pada uji data dan $10 \%$ digunakan uji pada tampilan GUI. Untuk proses training data digunakan percobaan dengan ketentuan nilai net.trainParam.goal $=0.0001$, net.trainParam.lr $=0.01$, dan net.trainParam.epochs $=1000$ dengan jumlah hidden node 1 sampai 100 dengan pemilihan nilai RMSE terkecil, sehingga memperoleh nilai RMSE sebesar 10,4812 pada hidden node ke 55. Untuk $15 \%$ data yang di ujikan memperoleh nilai RMSE 5,8301 dan 10\% data yang diujikan pada GUI mendapatkan hasil tertinggi sebesar 3445,87 rpm.

Pada pengujian karakteristik rasio input Gasoline-Biogas terhadap kecepatan putaran tanpa menggunakan JST mendapatkan hasil minimum sebesar 2900 rpm hasil maksimum 3090 rpm, pada percobaan menggunakan GUI mendapatkan hasil kecepatan putaran minimum sebesar 3438,73 dan 
hasil kecepatan putaran maksimum sebesar $3438,86 \mathrm{rpm}$.

Dari data yang telah diperoleh, dengan adanya penambahan flowrate biogas setiap L/menitnya berpengaruh terhadap data keluaran dari GUI yang dibuat, dimana semakin meningkatnya flowrate biogas yang diberikan terhadap rasio gasoline maka semakin tinggi juga hasil keluaran kecepatan putaran yang didapatkan. Sehingga untuk mencapai nilai performansi engine terbaik biogas bisa dijadikan untuk bahan bakar penunjang yang baik bagi kinerja generator-set yang akan digunakan.

\section{PENUTUP}

\section{Kesimpulan}

Kesimpulan yang didapatkan dari penelitian ini yaitu untuk menentukan karakterisasi kecepatan putaran berdasarkan rasio input terbaik menggunakan Jaringan Syaraf Tiruan untuk menggunakan 300 data dengan $75 \%$ untuk training dan 25\% untuk uji, nilai net.trainParam.goal $=0.0001$, net.trainParam.lr $=0.01$, dan net.trainParam.epochs $=1000$.

Hasil training JST memperoleh nilai RMSE sebesar 10,4812 pada node ke 55 dan hasil uji memperoleh nilai RMSE sebesar 5,8301. Setiap penambahan flowrate biogas dari $0,5 \mathrm{~L} /$ menit hingga $5 \mathrm{~L} /$ menit yang diberikan dengan rasio gasoline pada range $0.01 \mathrm{~L} /$ menit hingga 0,016 L/menit. Hasil dari JST menunjukkan kecepatan putar mengalami kenaikan dengan kecepatan putaran tertinggi sebesar 3445,87 rpm.

\section{Saran}

Saran yang dapat diberikan untuk pengembangan penelitian selanjutnya sebagai berikut.

a. Pengujian yang dilakukan sebaiknya membuat alat purifikasi yang minimalis dan praktis agar mudah daam implementasi secara langsung dari reaktor biogas ke generator set.

b. Wiring system diharapkan dapat lebih compact saat dilakukan eksperimen yang bersifat mobile

\section{DAFTAR PUSTAKA}

Abdurrahman, A., Soehartanto, T., 2014. Analisis Karakterisasi Water Scrubber Pada Alat Purifikasi Biogas Tipe Kombinasi Spray Tower dan Tray Tower. Seminar Nasional Teknologi Terapan, Universitas Gajah Mada, Yogyakarta.
Awogbemi., Omojola., Adeyemo., Babatunde, S., 2015. Development and Testing of Biogas Petrol Blend as an Alternative Fuel For Spark Ignition Engine. International Journal of Scientific and Technology Research. Vol. 4. Available at : http://www.indjst.org

Bastida, H., Carlos, E., Abeyesekerra, M., 2017. Sch. Eng. 142, 1282-1287.

Chuwang, S., Shujian, Y., Chaoyi, W., Meizhi, X., 2011. The Design and Study on The Mixture Control System of The Biogas - Gasoline Dual Fuel Engine. Guangxi University Nanning, China.

Harahap, F., 1980. Teknologi Gas Bio. Bandung : Pusat Teknologi Pembangunan ITB.

K. Gurney, An Introduction to Neural Networks, CRC Press, 2003.

Puspaningrum., 2006. Pengantar Jaringan Syaraf Tiruan. Yogyakarta : Andi Offset.

Setiawan, A. I., 2002. Memanfaatkan Kotoran Ternak. Jakarta : Cetakan Ketiga Penebar Swadya.

Verma, S., Das, L.M., Kaushik, 2017. Effects of varying composition of biogas on performance and emission characteristics of compression ignition engine using exergy analysis, Journal of Energy Elsevier, Ltd.

Yamasaki, Y., Kanno, M., Suzuki, Y., Kaneko, S., 2013. Development of an Engine Control System Using City Gas and Biogas Fuel Mixture. Department of Mechanical Engineering, The University of Tokyo, Japan.

Zuhri, T. 2015. Karakterisasi Unjuk Kerja Mesin Diesel Generator set Sistem Dual Fuel Solar dan Syngas Batubara. Pascasarjana. Teknik Mesin, Institut Teknologi Sepuluh Nopember, Surabaya.

Zed, F., Suharyani, Y.D., Rasyid, A., Rosdiana, D., 2014. Outlook Energi Indonesia. Jakarta : Dewan Energi Nasional. 